\title{
Performed Product Investigation
}

National Cancer Institute

\section{Source}

National Cancer Institute. Performed Product Investigation. NCI Thesaurus. Code C93432.

The completed process of evaluating a product after it has been returned to the manufacturer or reprocessor. 